\title{
SENSITIVITY OF EVAPOTRANSPIRATION ESTIMATED BY ORBITAL IMAGES UNDER INFLUENCE OF SURFACE TEMPERATURE
}

\author{
Roberto Filgueiras $^{1 *}$, Everardo C. Mantovani ${ }^{2}$, Daniel Althoff ${ }^{2}$, Santos H. B. Dias ${ }^{3}$, \\ Fernando F. da Cunha ${ }^{2}$
}

${ }^{1 *}$ Corresponding author. Federal University of Viçosa (UFV)/ Viçosa - MG, Brazil.

E-mail: roberto.f.filgueiras@ufv.br | ORCID ID: https://orcid.org/0000-0002-0186-8907

\section{KEYWORDS \\ energy balance, irrigated areas, remote sensing, NDVI.}

\begin{abstract}
Surface temperature (Ts) is a determining factor to obtain energy balance parameters, being relevant to understand the influence of this variable on the estimation of evapotranspiration. Thus, the objective of this study was to simulate errors in Ts estimation to verify the consequences of actual evapotranspiration (ETa) estimated by the SAFER (Simple Algorithm for Evapotranspiration Retrieving) model. For this, an image of the Landsat- 8 satellite was used to induce errors from $0.2 \mathrm{~K}$ to $10 \mathrm{~K}$ in the variable Ts, allowing verifying the consequences in the ETa data. After the estimations of Ts and ETa, the quantitative consequences and dynamics of Ts impact on the ETa data were verified along the different land uses in the study area. The results showed that the precise estimation of Ts is essential to obtain ETa accurately. The image of ETa errors presented the highest relative errors on the surface with exposed soils and with high Ts values. However, the highest residuals of ETa images occurred on the surfaces with milder Ts and higher evapotranspiration rates (irrigated surfaces).
\end{abstract}

\section{INTRODUCTION}

Evapotranspiration is a key factor for determining the water balance and water demand for crops (Sánchez et al., 2008; French et al., 2015). The correct estimation of this parameter is essential for increasing the productivity of irrigated agriculture (Allen et al., 2007; Alemu et al., 2014).

Remote sensing is a viable alternative for the spatial estimation of evapotranspiration, assisting in decisionmaking at levels of agricultural plots (Bastiaanssen et al., 1998a; Allen et al., 2007; Teixeira, 2010). For the spatialized evapotranspiration information to become a differential, it is necessary to know how accurate the estimation of this variable is (Djaman et al., 2016; Petropoulos et al., 2016, 2018), besides being relevant the knowledge of the influence of intermediate variables on the evapotranspiration phenomenon.

However, the estimation of evapotranspiration requires that the sensor on board the satellite can capture information emitted from the surface and relative to the electromagnetic spectrum of the thermal infrared
(Bastiaanssen, 2000; Li et al., 2013; Jimenez-Bello et al., 2015). This spectrum is necessary to estimate the surface temperature, a parameter required in the calculation of evapotranspiration (Bastiaanssen, 2000; Teixeira, 2010; Santos et al., 2011; Li et al., 2013; Andrade et al., 2014; Teixeira et al., 2015; Coaguila et al., 2017).

Several models can estimate the actual evapotranspiration (ETa) by means of satellite images, for example, the models SEBAL - Surface Energy Balance Algorithm for Land (Bastiaanssen et al., 1998a; Bastiaanssen et al., 1998b; Bhattarai et al., 2017), METRIC - Mapping EvapoTranspiration at high Resolution with Internalized Calibration (Allen et al., 2007), and SAFER Simple Algorithm for Evapotranspiration Retrieving (Teixeira, 2010).

Methodologies in the SEBAL and METRIC models require spectral data from the thermal region to calculate surface temperature (Ts) and, consequently, find radiation balance, soil heat flux, sensible heat flux, latent heat flux, evaporative fraction, and ETa (Liou \& Kar, 2014). The

\footnotetext{
${ }^{2}$ Federal University of Viçosa (UFV)/ Viçosa - MG, Brazil.

${ }^{3}$ Ponta Grossa State University (UEPG)/ Ponta Grossa - PR, Brazil.
} 
SAFER model is based on a simpler parameterization, in which Ts is already used in the calculation of the evapotranspiration fraction (r) and then ETa estimation.

However, due to the simplicity of the SAFER model and its high applicability potential in irrigation management consultancies, it is important to know more about the sensitivity that the ETa estimated by this model has as a function of Ts. It is a fact that there are models more sensitive to surface temperature errors than others are, such as two-source models (Zhang et al., 2016).

Given the importance of estimating ETa in typical regions of irrigated agriculture, coupled with the unanimity of models in using Ts to predict ETa, and considering that Ts is a key parameter in estimating evapotranspiration (Hain \& Anderson, 2017), it is relevant to know how possible errors in Ts estimation can affect the estimation of evapotranspiration. This study aimed to simulate errors in Ts estimation to verify the consequences generated in ETa estimated using the SAFER model.

\section{MATERIAL AND METHODS}

\section{Study area}

The study area used to carry out the simulation is located in the western region of Bahia State, municipality of São Desidério, at the pairs of geographical coordinates X1414,315; Y1-8,630,725 and X2-441,619; Y2-8,613,014, Datum WGS-84, UTM (Universal Transverse Mercator) projection, zone $23 \mathrm{~S}$ (Figure 1), totaling an area of approximately $500 \mathrm{~km}^{2}$.
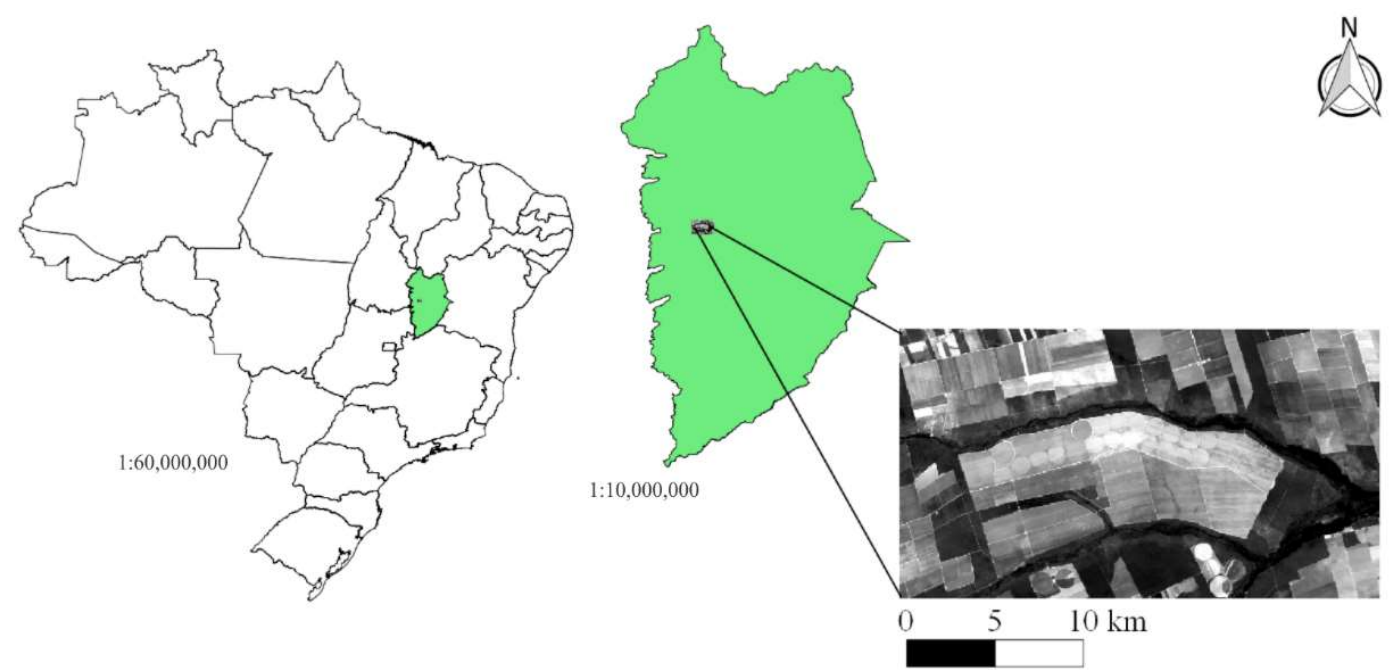

Western region of Bahia state

FIGURE 1. Study area used to simulate the sensitivity of actual evapotranspiration to the surface temperature in relation to the western mesoregion of Bahia State and Brazil.

An image from the satellite Landsat-8 Collection 1, Level 1 processing, orbit/point 220/069, from March 6, 2015, was used to perform this simulation. This image was acquired on the platform maintained by the United States Geological Survey (USGS) called EarthExplorer. The meteorological data were acquired through an automatic station (Davis, Vantage Pro Plus, Hayward, CA) present in the study area. The data collected from this station were relative humidity $(\%)$, wind speed $\left(\mathrm{m} \mathrm{s}^{-1}\right)$, solar radiation $\left(\mathrm{W} \mathrm{m}^{-2}\right.$ ), and mean, maximum, and minimum temperatures $\left({ }^{\circ} \mathrm{C}\right)$. These data were used to calculate the reference evapotranspiration (ETo), which was used to estimate ETa using the SAFER model. ETo was estimated according to the Penman-Monteith equation, recommended as standard by the FAO-56 bulletin (Allen et al., 1998).

After estimating ETo, ETa was estimated using images. ETa estimation was divided into stages: image preprocessing, calculation of intermediate variables (SAFER variables) of the model, and ETa estimation by the SAFER methodology.

\section{Image preprocessing}

Before the estimation of evapotranspiration by the SAFER algorithm, a radiometric conversion (Ponzoni et al., 2012) and atmospheric correction were performed Chavez Jr (1996).
The radiometric conversion consists of the conversion of digital numbers $(\mathrm{DN})$ of the pixel to physical values of radiance and reflectance. The conversion was performed for each band of the image obtained by the Landsat-8 satellite (Equation 1) (Ariza, 2013).

$$
\mathrm{L}_{\lambda}=\mathrm{M}_{\mathrm{L}} \mathrm{Q}_{\mathrm{cal}}+\mathrm{A}_{\mathrm{L}}
$$

Where:

$\mathrm{L} \lambda$ is the top-of-atmosphere radiance $\left(\mathrm{W} \mathrm{m}^{-2} \mathrm{sr}^{-1} \mu \mathrm{m}^{-1}\right)$;

$\mathrm{M}_{\mathrm{L}}$ is the specific multiplicative (gain) factor for each band;

$A_{L}$ is the specific additive (offset) factor for each band, and

$\mathrm{Q}_{\mathrm{cal}}$ is the quantized and calibrated standard product pixel value (DN). Gain and offset are values provided by the image metadata file.

The conversion of radiance to reflectance $(\rho \lambda)$ of the images obtained by the OLI sensor (bands 2 to 7) were performed according to [eq. (2)] (Allen et al., 2002; Teixeira et al., 2015).

$$
\rho_{\mathrm{P}}=\frac{\pi \mathrm{L}_{\lambda} \mathrm{d}^{2}}{\operatorname{ESUN}_{\lambda} \cos Z}
$$


Where:

$\rho_{\mathrm{P}}$ is the top-of-atmosphere reflectance (dimensionless);

$\mathrm{ESUN}_{\lambda}$ is the solar exoatmospheric irradiances corresponding to each band of the OLI instrument ( $\mathrm{W} \mathrm{m}^{-2} \mu \mathrm{m}^{-1}$ );

$\mathrm{Z}$ is the solar zenith angle (radians), and

$\mathrm{d}$ is the Earth-Sun distance (astronomical unit).

The methodology called Dark Object Subtraction (DOS), proposed by (Chavez Jr, 1988), using the Semiautomatic Classification plugin (Congedo, 2016) through QGIS 2.8 (QGIS Development Team, 2017) was used to mitigate the effects of the atmosphere.

\section{SAFER variables}

The spectral radiance of band 10 was converted into top-of-atmosphere brightness temperature $\left(\mathrm{T}_{\text {bri }}\right)$ using the thermal constants provided by the image metadata file (Equation 3).

$$
\mathrm{T}_{\mathrm{bri}}=\frac{\mathrm{K} 2}{\operatorname{Ln}\left(\frac{\mathrm{K} 1}{\mathrm{~L}_{\lambda}}+1\right)}
$$

Where:

$\mathrm{T}_{\text {bri }}$ is the top-of-atmosphere brightness temperature (K);

$\mathrm{K} 1$ is the thermal constant specific for the band (W $\mathrm{m}^{-2} \mathrm{sr}^{-1} \mu \mathrm{m}^{-1}$ ), and

$\mathrm{K} 2$ is the thermal constant specific for the band $(\mathrm{K})$.

The methodological procedure of Teixeira et al. (2017) to obtain the required parameters was used to calculate evapotranspiration by the SAFER method. The required parameters are planetary albedo (Equation 4), surface albedo (Equation 5), surface temperature (Equation 6 ), and normalized difference vegetation index (NDVI) (Equation 7). The bands B2 to B7, which correspond to the spectra of blue (B2, 0.45-0.51 $\mu \mathrm{m}$ ), green (B3, 0.53-0.59 $\mu \mathrm{m})$, red (B4, 0.64-0.67 $\mu \mathrm{m}$ ), near infrared (B5, 0.85-0.88 $\mu \mathrm{m})$, short wavelength infrared $1(\mathrm{~B} 6,1.57-1.65 \mu \mathrm{m})$, short wavelength infrared 2 (B7, 2.11-2.29 $\mu \mathrm{m})$ were used to calculate the planetary albedo.

$$
\begin{aligned}
& \alpha_{\text {top }}=\Sigma\left(\omega_{\lambda} \rho_{\lambda}\right) \\
& \alpha_{0}=0.61 \alpha_{\text {top }}+0.08 \\
& \mathrm{~T}_{0}=1.07 \mathrm{~T}_{\text {bri }}-20.17 \\
& \mathrm{NDVI}=\frac{\rho_{\mathrm{B} 5}-\rho_{\mathrm{B} 4}}{\rho_{\mathrm{B} 5}+\rho_{\mathrm{B} 4}}
\end{aligned}
$$

Where:

$\alpha_{\text {top }}$ is the planetary albedo (dimensionless);

$\omega_{\lambda}$ is the ratio between the quantity of short-wave radiation received from the sun at the top of the atmosphere in a given range and the sum for all bands used for $\alpha_{\text {top }}$ (dimensionless); $\alpha_{0}$ is the surface albedo (dimensionless);

$\mathrm{T}_{0}$ is the surface temperature;

$\rho_{\mathrm{B} 5}$ is the reflectance over the wavelength ranges in the near-infrared region of the solar spectrum, and

$\rho_{\mathrm{B} 4}$ is the reflectance over the wavelength ranges in the red region of the solar spectrum.

Reflectances listed above refer to bands 5 and 4 for the Landsat- 8 satellite, respectively. The ratio $\omega_{\lambda}$ was obtained using [eq. (8)]:

$$
\omega_{\lambda}=\frac{\operatorname{ESUN}_{\lambda \mathrm{i}}}{\operatorname{ESSUN}_{\lambda \mathrm{i}}}
$$

Where:

$\sum E S U N \lambda_{i}$ is the sum of short-wave solar radiation in all bands at the top of the atmosphere ( $\mathrm{W} \mathrm{m}^{-2} \mu \mathrm{m}^{-1}$ ), and

$\operatorname{ESUN} \lambda_{\mathrm{i}}$ is the solar irradiation in band $\mathrm{i}$.

\section{Actual evapotranspiration - ETa}

After obtaining the variables, the SAFER algorithm was used to model the ratio between the actual and reference evapotranspiration $(\mathrm{ETa} / \mathrm{ETo})$ at the time of satellite pass over the area (Equation 9), being this ratio named $r$ :

$$
r=\exp \left[\alpha+\beta\left(\frac{\mathrm{T}_{0}}{\alpha_{0} \times \mathrm{NDVI}}\right)\right]
$$

Where:

$\alpha$ and $\beta$ were 1.8 and $-0.008{ }^{\circ} \mathrm{C}^{-1}$, respectively, as suggested by Teixeira et al. (2013) for semi-arid conditions.

The calculation of actual evapotranspiration is independent on the user's knowledge regarding land use or the crop used in the field since the ratio $r$ allows inferring on the crop coefficient. After obtaining $r$, ETo obtained by the FAO-56 method (Allen et al., 1998) was multiplied by the resulting image of [eq. (9)], resulting in the daily actual evapotranspiration of SAFER (ETa), as shown in [eq. (10)]:

$$
\mathrm{ETa}=\mathrm{r}^{*} \text { ETo }
$$

Where:

ETa is the actual evapotranspiration obtained by the SAFER algorithm $\left(\mathrm{mm} \mathrm{d}^{-1}\right)$.

Because the objective was to analyze the influence of Ts on ETa, we needed to re-estimate ETa for the different errors added in the Ts image, as detailed in the next section.

\section{Methodology of error addition in Ts}

The following errors were added in the Ts image to verify the influence of Ts on the sensitivity of ETa estimated by SAFER: 0.2, 0.5, 1, 2, 3, 4, 5, and $10 \mathrm{~K}$. Errors were incrementally added in Ts to analyze the impact they cause on the different surfaces of the study area. 
Therefore, eight Ts images were generated with the increment of the mentioned errors. After error addition, ETa were estimated using Ts information with errors. This procedure was performed to analyze the residuals between ETa without error and ETa with error addition in Ts.

\section{Analysis of ETa sensitivity under the influence of surface temperature}

The relative percentage error between ETa estimated with Ts errors and ETa estimated without Ts errors was calculated to evaluate the sensitivity of ETa data under the influence of positive errors on Ts. Also, the residuals between ETa estimated with errors and ETa without error addition were calculated.

\section{RESULTS AND DISCUSSION}

The behavior of NDVI estimated for the day of analysis is shown in Figure 2. NDVI shows the dynamics of vegetation vigor and hence allows inferring with the spatial behavior of Ts and ETa.

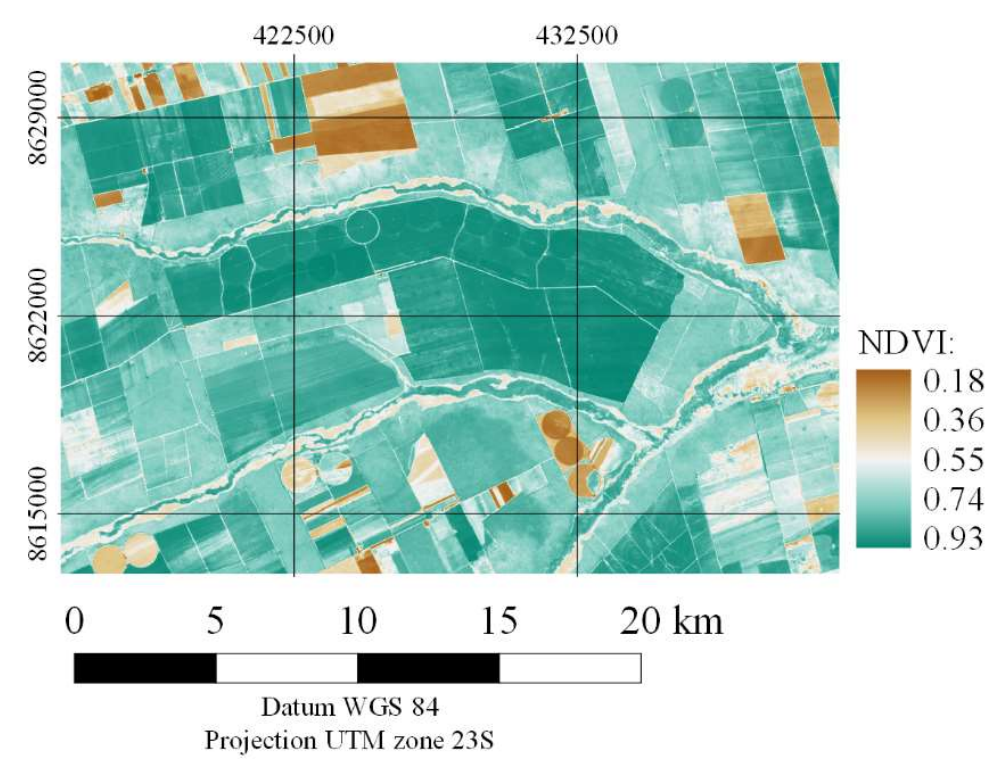

FIGURE 2. NDVI for the study area on March 6, 2015.

NDVI (Figure 2) showed that the region presented areas with a predominance of vegetation in its pixels, which was evidenced by high NDVI values (above 0.74). NDVI also showed a high amplitude in its values, which allowed the analysis of the influence of Ts on ETa in the most different terrestrial surfaces (amplitude of 0.18 to 0.93 of NDVI values). For Figure 2, regions with NDVI values of 0.18 to 0.36 represent exposed soils and areas with straw. NDVI values close to 0.36 to 0.55 represent plots with crop in development and crops in the senescence processes.
Figures $3 \mathrm{~A}$ and $\mathrm{B}$ show the images of Ts and ETa, respectively, estimated by the SAFER model on March 6, 2015. These images are free from purposive errors, serving as a basis for the following discussions. Figure 3A shows that Ts has an amplitude ranging from $296 \mathrm{~K}$ to $312 \mathrm{~K}$. Sites with lower temperatures are linked to those with higher evapotranspiration values, the reverse being true (Figures $3 \mathrm{~A}$ and $2 \mathrm{~B}$ ) since the more intense the evaporation phenomenon is, the higher the latent heat transfer and thus the surface cooling (Li et al., 2013; Jimenez-Bello et al., 2015).

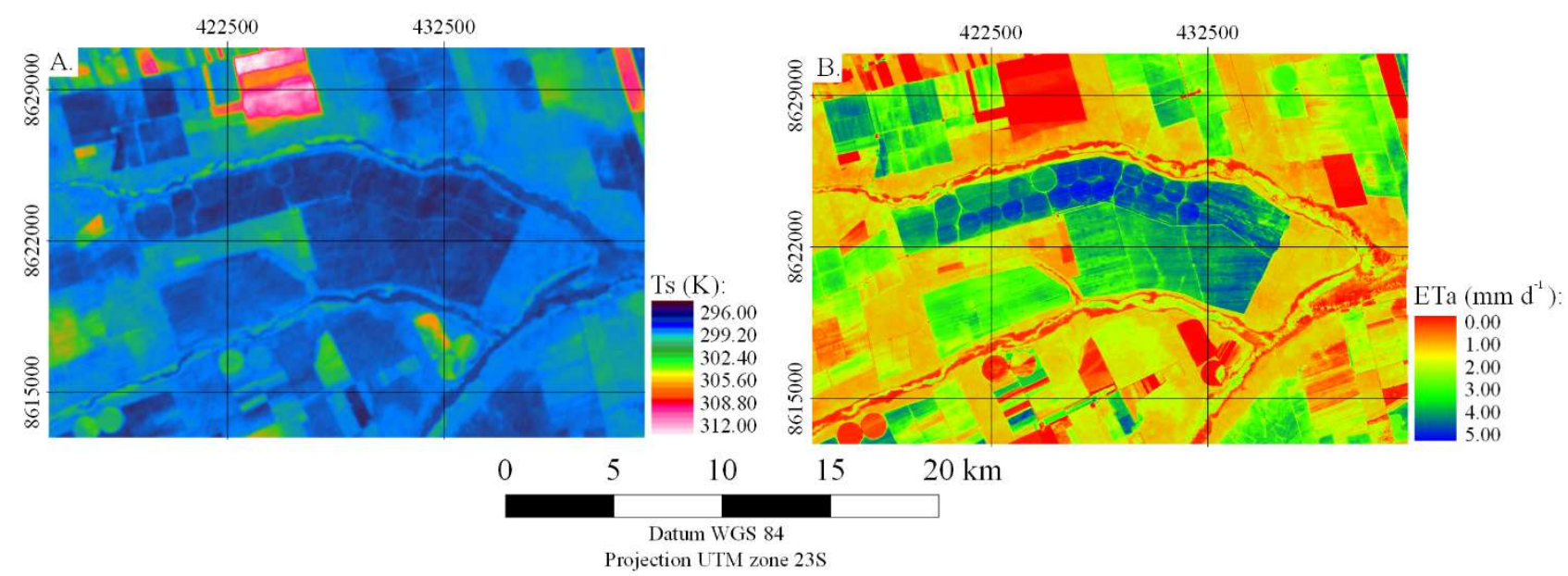

FIGURE 3. Surface temperature (Ts) (A) and actual evapotranspiration (ETa) (B) for the study area on March 6, 2015. 
By increasing the positive error in the Ts product, center pivot regions, which had a behavior similar to cold pixels, now have characteristics of a region with low humidity. Therefore, these regions resembled a hot pixel behavior, being the estimation of evapotranspiration underestimated (Bastiaanssen, 2000; Teixeira et al., 2009; Machado et al., 2014; Bhattarai et al., 2017).

According to Allen et al. (2002), the cold pixel should be selected to represent an agricultural area that presents vegetation with closed canopy and well irrigated, with sensible heat flux considered zero. This condition is adequate for the center pivots of the study area, for the date when the image was captured. In addition, the hot pixel can be described as an agricultural area of exposed soil, low humidity, and where the latent heat flux is considered zero.

The relative percentage error in which Ts allowed estimating ETa in the study area was analyzed to know the regions significantly affected by the addition of Ts errors (Figure 4).
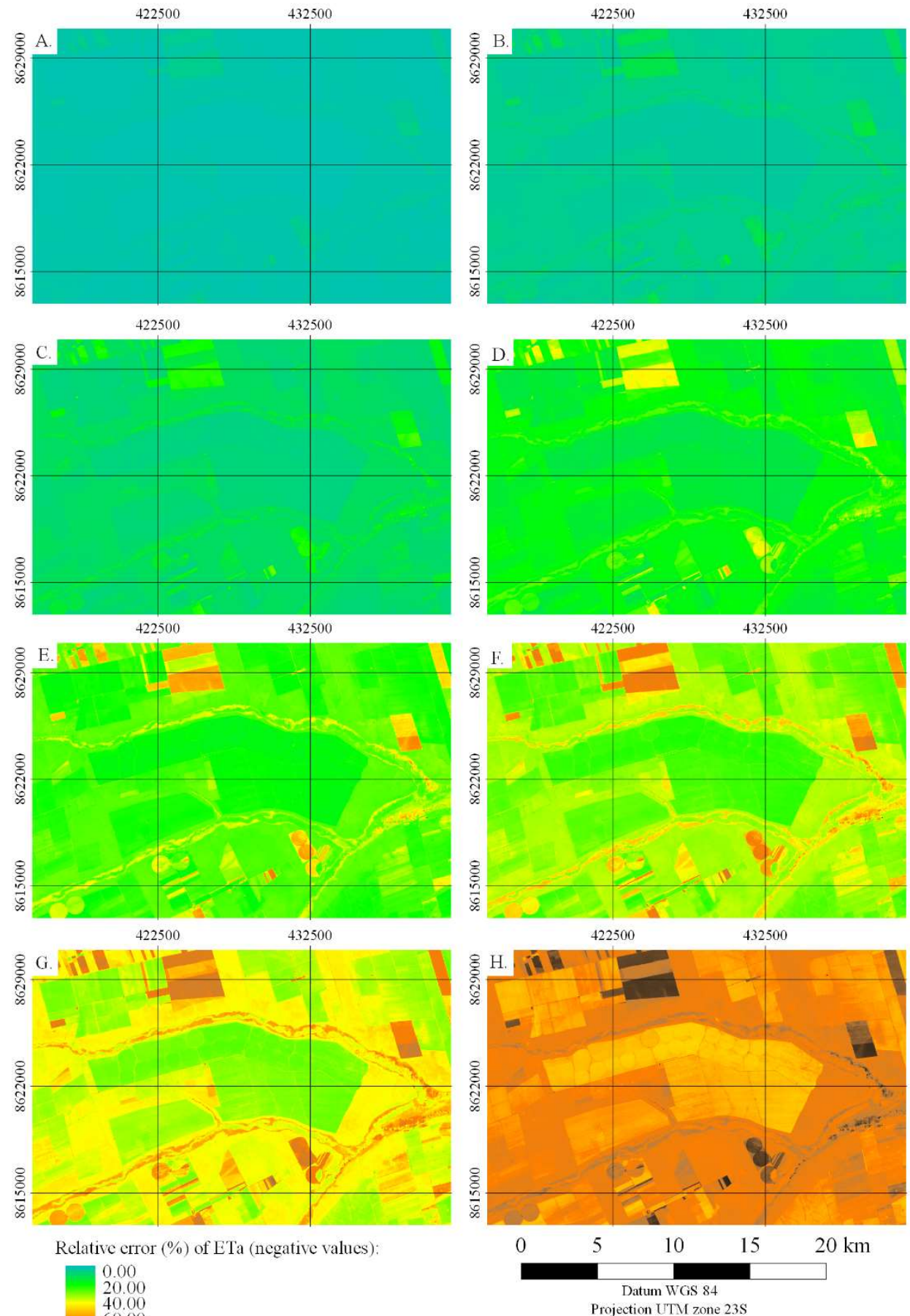

FIGURE 4. Relative percentage error of the actual evapotranspiration with the following error addition $(+)$ in the surface temperature: $0.2 \mathrm{~K}(\mathrm{~A}), 0.5 \mathrm{~K}(\mathrm{~B}), 1 \mathrm{~K}(\mathrm{C}), 2 \mathrm{~K}(\mathrm{D}), 3 \mathrm{~K}(\mathrm{E}), 4 \mathrm{~K}(\mathrm{~F}), 5 \mathrm{~K}(\mathrm{G})$, and $10 \mathrm{~K}(\mathrm{H})$. 
Figure 4 shows that the most affected regions in relative percentage to ETa are regions with a high Ts and predominance of exposed soils (low NDVI values). These regions presented lower intensity evapotranspiration as they already fit the characteristics of regions for selecting hot pixel, as previously defined (Bhattarai et al., 2017).

In interpreting Figure 4 and analyzing the occurrences of dynamics of relative errors deepening the energy balance process, it is verified that a positive error in Ts estimation leads to a reduction in the available energy in the system, i.e., in the surface radiation balance. It is due mainly to the Stefan-Boltzmann Law equation, which determines that a body emits long-wave radiation proportional to the fourth power of its temperature (Angelini et al., 2017). Thus, if an error occurs in Ts, it will be raised to the fourth power in the estimation of long-wave radiation emission. The overestimation in long-wave radiation results in a lower radiation balance, and hence, there will be an underestimation of the energy available to perform the other physical and biological processes of the energy balance equation.

When analyzing Figure 4 and performing a reflection on the theory of soil heat flux (energy balance), it is perceived that it is raised with an increase in Ts. Soil heat flow increases mainly because the temperature of this surface is considered higher as it is the portion of the energy balance equation responsible for soil heating by conduction. The empirical equation developed by Bastiaanssen (2000) demonstrates in mathematical terms that this relation is true.

The analysis of relative errors of Figure 4, starting from theoretical reasoning on sensible heat flow, showed that it should also increase as Ts increases caused by the added errors. This finding is true since this phenomenon represents the energy expended in the energy balance for air heating near the surface, which occurs by convection. The additional positive error in Ts causes the temperature gradient to rise, distancing the surface temperature $(\mathrm{Z} 1)$ from the air temperature near the surface (Z2), causing the surface to increase in a heat loss rate to the atmosphere due to this difference. The analysis of the sensible heat flow equation in SEBAL (Bastiaanssen et al., 1998b; Allen et al., 2002), showed this occurrence in algebraic terms.

However, the fact that the relative error was higher in regions with low ETa rates does not mean that these surfaces are the most affected by surface temperature errors. Figure 5 shows the absolute residuals of ETa caused by different errors added in Ts product. 

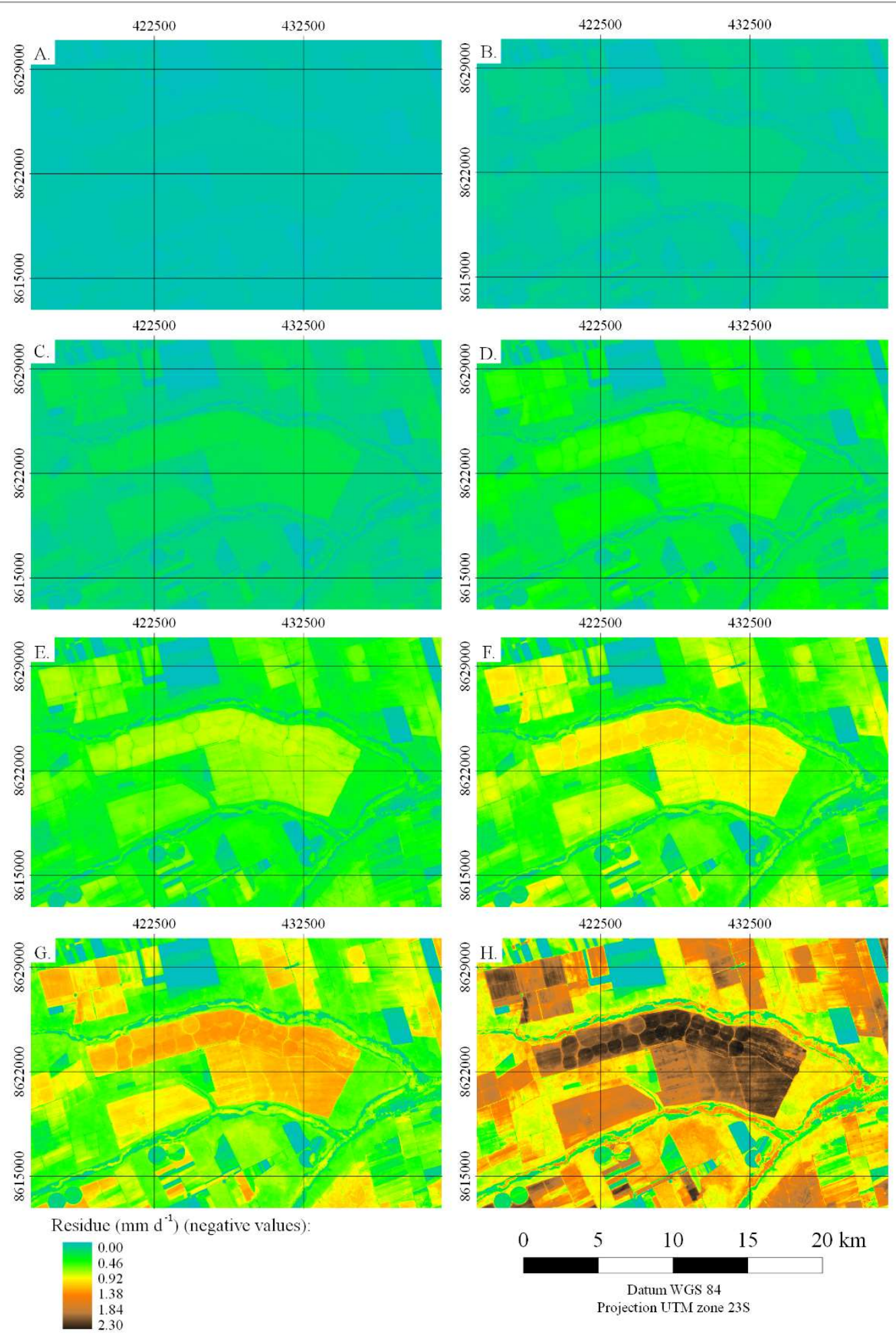

FIGURE 5. Residual between the simulated evapotranspiration with positive surface temperature errors and evapotranspiration without error addition: additions of $0.2 \mathrm{~K}(\mathrm{~A}), 0.5 \mathrm{~K}(\mathrm{~B}), 1 \mathrm{~K}(\mathrm{C}), 2 \mathrm{~K}(\mathrm{D}), 3 \mathrm{~K}(\mathrm{E}), 4 \mathrm{~K}(\mathrm{~F}), 5 \mathrm{~K}(\mathrm{G})$, and $10 \mathrm{~K}(\mathrm{H})$ in the surface temperature.

By observing Figure 5 and relating it to Figure 3, residuals in millimeters were more accentuated on surfaces that have higher evapotranspiration values, such as the center pivots located in the study area. Most of these center pivots were on the crop at advanced development stages at image time. It highlights the importance of accurately estimating Ts, as the estimation of evapotranspiration is usually processed for irrigated crops.

Figure 6 shows the histograms of residuals of ETa caused by different errors in Ts estimations. In this case, the mean errors in the images were $0.034(0.2 \mathrm{~K}), 0.084(0.5$ K), $0.165(1 \mathrm{~K}), 0.317(2 \mathrm{~K}), 0.455(3 \mathrm{~K}), 0.582(4 \mathrm{~K}), 0.698$ $(5 \mathrm{~K})$, and $1.148 \mathrm{~mm} \mathrm{~d}^{-1}(10 \mathrm{~K})$. Considering that the reference evapotranspiration in the study area by the Penman-Monteith method (Allen et al., 1998) was of the order of $3.37 \mathrm{~mm} \mathrm{~d}^{-1}$ on March 6, 2015, the estimation in the surface temperature error caused a significant impact in obtaining ETa. 

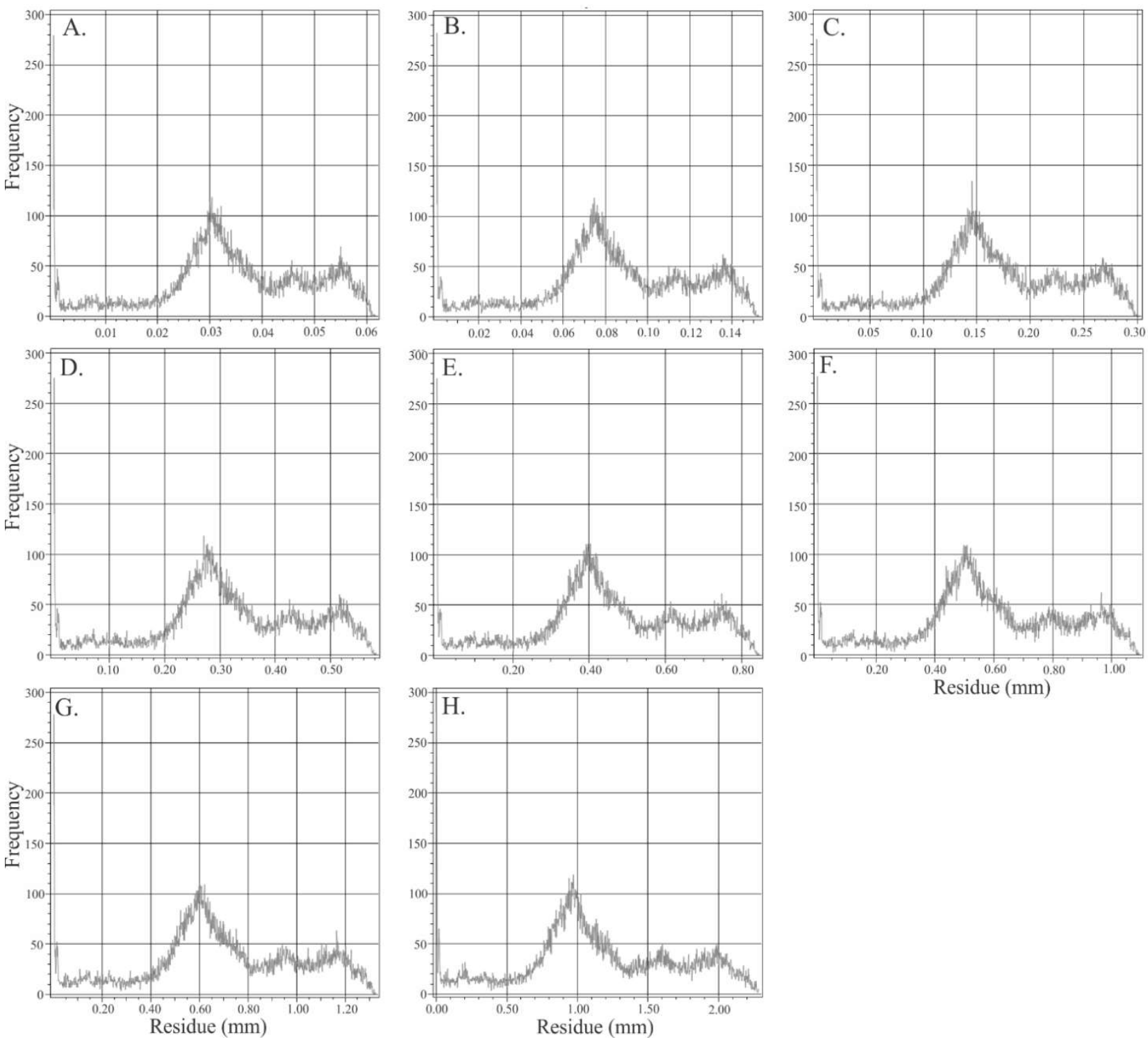

FIGURE 6. Histograms of residuals between the actual evapotranspiration without and with error addition in the surface temperature: additions of $0.2 \mathrm{~K}(\mathrm{~A}), 0.5 \mathrm{~K}(\mathrm{~B}), 1 \mathrm{~K}(\mathrm{C}), 2 \mathrm{~K}(\mathrm{D}), 3 \mathrm{~K}(\mathrm{E}), 4 \mathrm{~K}(\mathrm{~F}), 5 \mathrm{~K}(\mathrm{G})$, and $10 \mathrm{~K}(\mathrm{H})$ in the surface temperature.

A significant frequency of points with residuals from 1.7 to $2.3 \mathrm{~mm} \mathrm{~d}^{-1}$ was observed when analyzing the extreme right tail of the histograms in Figure 6, focusing on Figure $6 \mathrm{H}$. These points are related to center pivots that present ETa in the order of 4.5 to $5 \mathrm{~mm} \mathrm{~d}^{-1}$ (Figure $2 \mathrm{~B}$ ).
Figure 7 shows, through boxplot graphs, the descriptive statistics of the residual of ETa for the different intensities of errors applied to the Ts product, which allows verifying the effects that Ts errors caused on ETa of the surface of the study area.

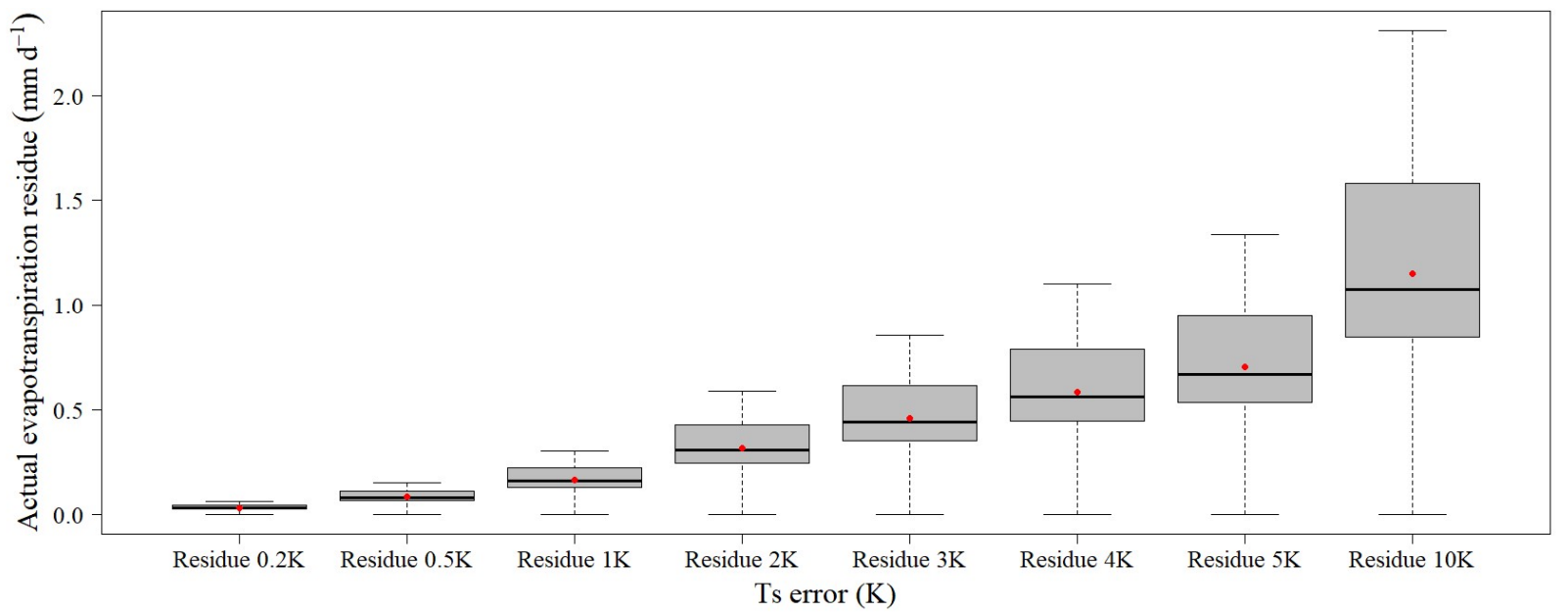

FIGURE 7. Descriptive statistics of the different residuals generated in the actual evapotranspiration for the different intensities of the surface temperature error. 
After analyzing the results, it is perceived that accurately estimating Ts is essential for reliable estimations of evapotranspiration. Small errors in Ts may lead to large errors in the magnitude of evapotranspiration of the surface depending on the land use present in it. This fact was perceived through a qualitative analysis of NDVI (Figure 2) with images of ETa errors caused by the additional Ts errors (Figures 4 and 5).

Thus, if the intention is to manage irrigation with orbital data, attention should be given to the coherent Ts estimation, being important to analyze the estimation calculations before continuing to obtain ETa.

\section{CONCLUSIONS}

The surface temperature has a considerable influence on the ETa data estimated by satellites, being important that this variable be correctly estimated for an assertive evapotranspiration demand.

Residuals with higher magnitudes in ETa in the study region are present on surfaces that have higher daily ETa values.

The relative percentage error in the studied region is higher on surfaces that have lower evapotranspiration, usually in regions with high Ts.

\section{ACKNOWLEDGMENTS}

We thank the anonymous reviewers and the editor for their careful reading and valuable comments, which helped us to improve the manuscript. We thank the financial support ( $\mathrm{PhD}$ scholarship) given by Conselho Nacional de Desenvolvimento Científico e Tecnológico CNPq (Contrac number: 148636/2016-0) and Coordenação de Aperfeiçoamento de Pessoal de Nível Superior - CAPES (Finance Code 001) to the first author. We also thank the Department of Agriculture Engineering (DEA), the Center of Reference in Water Resources CRRH and the Group of Studies and Solutions for Irrigated Agriculture - GESAI of the Federal University of Viçosa for supporting the researchers.

\section{REFERENCES}

Alemu H, Senay G, Kaptue A, Kovalskyy V (2014) Evapotranspiration Variability and Its Association with Vegetation Dynamics in the Nile Basin, 2002-2011. Remote Sensing 6(7):5885-5908. DOI: https://doi.org/10.3390/rs6075885

Allen RG, Pereira LS, Raes D, Smith M (eds) (1998) Crop evapotranspiration - guidelines for computing crop water requirements. FAO, 297p.

Allen RG, Tasumi M, Trezza R, Waters R, Bastiaassen W (2002) Surface energy balance algorithm for land (SEBAL) - Advanced training and User's Manual. Kimberly, Idaho Implementation. 98p.

Allen RG, Tasumi M, Trezza R (2007) Satellite-based energy balance for mapping evapotranspiration with internalized calibration (METRIC) - Model. Journal of irrigation and drainage engineering 133(4):380-394.
Andrade RG, Sediyama G, Soares VP, Gleriani JM, Menezes SJMC (2014) Estimativa da produtividade da cana-de-açúcar utilizando o Sebal e imagens Landsat. Revista Brasileira de Meteorologia 29(3):433-442. DOI: https://doi.org/10.1590/0102-778620130022

Angelini LP, Silva PCBS, Fausto MA, Machado NG, Biudes MS (2017) Balanço de energia nas condições de mudanças de uso do solo na Região Sul do Estado de Mato Grosso. Revista Brasileira de Meteorologia 32(3):353-363. DOI: https://doi.org/10.1590/0102-77863230003

Ariza A (2013) Descripción y Corrección de Productos Landsat 8 LDCM (Landsat Data Continuity Mission). Bogotá, Instituto Geográfico Agustín Codazzi, 45p.

Bastiaanssen WGM (2000) SEBAL-based sensible and latent heat fluxes in the irrigated Gediz Basin, Turkey. Journal of hydrology 229(1):87-100. DOI: https://doi.org/10.1016/S0022-1694(99)00202-4

Bastiaanssen WGM, Menenti M, Feddes RA, Holtslag AAM (1998) A remote sensing surface energy balance algorithm for land (SEBAL) 1. Formulation. Journal of Hydrology 212-213:198-212. DOI: https://doi.org/10.1016/S0022-1694(98)00253-4

Bastiaanssen WGM, Pelgrum H, Wang J, Ma Y, Moreno JF, Roerink GJ, van der Wal T (1998) A remote sensing surface energy balance algorithm for land (SEBAL) 2. Validation. Journal of Hydrology 212(1-4):213-229. DOI: https://doi.org/10.1016/S0022-1694(98)00254-6

Bhattarai N, Quackenbush LJ, Im J, Shaw SB (2017) A new optimized algorithm for automating endmember pixel selection in the SEBAL and METRIC models. Remote Sensing of Environment 196:178-192. DOI: https://doi.org/10.1016/j.rse.2017.05.009

Chavez Jr PS (1996) Image-Based Atmospheric Corrections: Revisited and Improved. Photogrammetric Engineering and Remote Sensing 62(9):1025-1036.

Chavez Jr PS (1988) An improved dark-object subtraction technique for atmospheric scattering correction of multispectral data. Remote sensing of environment 24(3):459-479. DOI: https://doi.org/10.1016/00344257(88)90019-3

Coaguila DN, Hernandez FBT, Teixeira AHC, Franco RAM, Leivas JF (2017) Water productivity using SAFER Simple Algorithm for Evapotranspiration Retrieving in watershed. Revista Brasileira de Engenharia Agrícola e Ambiental 21(8):524-529. DOI:

https://doi.org/10.1590/1807-1929/agriambi.v21n8p524-529

Congedo L (2016) Semi-automatic classification plugin documentation: Release 5.0.1.1. Roma, Sapienza University of Rome, 201p.

Djaman K, Tabari H, Balde AB, Diop L, Futakuchi K, Irmak S (2016) Analyses, calibration and validation of evapotranspiration models to predict grass-reference evapotranspiration in the Senegal river delta. Journal of Hydrology: Regional Studies 8:82-94. DOI: https://doi.org/10.1016/j.ejrh.2016.06.003 
French AN, Hunsaker DJ, Thorp KR (2015) Remote sensing of evapotranspiration over cotton using the TSEB and METRIC energy balance models. Remote Sensing of Environment 158:281-294. DOI: https://doi.org/10.1016/j.rse.2014.11.003

Hain CR, Anderson MC (2017) Estimating morning change in land surface temperature from MODIS day/night observations: Applications for surface energy balance modeling: Estimating Morning $\triangle$ LST From MODIS. Geophysical Research Letters 44(19):9723-9733. DOI: https://doi.org/10.1002/2017GL074952

Jimenez-Bello MA, Castel JR, Testi L, Intrigliolo DS (2015) Assessment of a Remote Sensing Energy Balance Methodology (SEBAL) Using Different Interpolation Methods to Determine Evapotranspiration in a Citrus Orchard. IEEE Journal of Selected Topics in Applied Earth Observations and Remote Sensing 8(4):1465-1477. DOI: https://doi.org/10.1109/JSTARS.2015.2418817

Li Z, Liu X, Ma T, Kejia D, Zhou Q, Yao B, Niu T (2013) Retrieval of the surface evapotranspiration patterns in the alpine grassland-wetland ecosystem applying SEBAL model in the source region of the Yellow River, China. Ecological Modelling 270:64-75. DOI: https://doi.org/10.1016/j.ecolmodel.2013.09.004

Liou Y-A, Kar S (2014) Evapotranspiration Estimation with Remote Sensing and Various Surface Energy Balance Algorithms-A Review. Energies 7(5):2821-2849. DOI: https://doi.org/10.3390/en7052821

Machado CC, Silva B, Albuquerque MB, Galvíncio JD (2014) Estimativa do balanço de energia utilizando imagens TM-Landsat 5 e o algoritmo SEBAL no litoral sul de Pernambuco. Revista Brasileira de Meteorologia 29(1):55-67. DOI: http://dx.doi.org/10.1590/S010277862014000100006

Petropoulos G, Srivastava P, Piles M, Pearson S (2018) Earth Observation-Based Operational Estimation of Soil Moisture and Evapotranspiration for Agricultural Crops in Support of Sustainable Water Management. Sustainability 10(1):181. DOI: https://doi.org/10.3390/su10010181

Petropoulos GP, Ireland G, Lamine S, Griffiths HM, Ghilain N, Anagnostopoulos V, Georgopoulou H (2016) Operational evapotranspiration estimates from SEVIRI in support of sustainable water management. International Journal of Applied Earth Observation and Geoinformation 49:175-187. DOI: https://doi.org/10.1016/j.jag.2016.02.006

Ponzoni F, Shimabukuro Y, Kuplich T (2012)

Sensoriamento remoto da vegetação. São Paulo, Oficina de Textos. 160p.
QGIS Development Team (2017) QGIS geographic information system. World, Open Source Geospatial Foundation. Avalable: http://qgis.osgeo.org

Sánchez JM, Scavone G, Caselles V, Valor E, Copertino VA, Telesca V (2008) Monitoring daily evapotranspiration at a regional scale from Landsat-TM and ETM+ data: Application to the Basilicata region. Journal of Hydrology 351(1-2):58-70. DOI:

https://doi.org/10.1016/j.jhydrol.2007.11.041

Santos TV, Fontana DC, Alves R de CM (2011) Avaliação de fluxos de calor e evapotranspiração pelo modelo SEBAL com uso de dados do sensor ASTER. Pesquisa Agropecuária Brasileira 45(5):488-496. DOI: http://dx.doi.org/10.1590/S0100-204X2010000500008

Teixeira AHC, Hernandez FBT, Lopes HL, SchererWarren M, Bassoi LH (2013) Modelagem espaçotemporal dos componentes dos balanços de energia e de água no Semiárido brasileiro. Campinas, Embrapa Monitoramento por satélite, 32p.

Teixeira AHC, Leivas JF, Andrade RG, Hernandez FBT (2015) Water productivity assessments with Landsat 8 images in the Nilo Coelho irrigation scheme. IRRIGA 1(2):1-10. DOI: https://doi.org/10.15809/irriga.2015v1n2p01

Teixeira AHC, Leivas JF, Hernandez FBT, Franco RAM (2017) Large-scale radiation and energy balances with Landsat 8 images and agrometeorological data in the Brazilian semiarid region. Journal of Applied Remote Sensing 11(1):016030-01-016030-15. DOI: https://doi.org/10.1117/1.JRS.11.016030

Teixeira AHC, Bastiaanssen WGM, Ahmad MD, Bos MG (2009) Reviewing SEBAL input parameters for assessing evapotranspiration and water productivity for the LowMiddle São Francisco River basin, Brazil. Agricultural and Forest Meteorology 149(3-4):462-476. DOI: https://doi.org/10.1016/j.agrformet.2008.09.016

Teixeira AHC (2010) Determining regional actual evapotranspiration of irrigated crops and natural vegetation in the São Francisco River Basin (Brazil) using remote sensing and Penman-Monteith Equation. Remote Sensing 2(5):1287-1319. DOI: https://doi.org/10.3390/rs0251287

Zhang K, Kimball JS, Running SW (2016) A review of remote sensing based actual evapotranspiration estimation: A review of remote sensing evapotranspiration. Wiley Interdisciplinary Reviews: Water 3(6): 834-853. DOI: https://doi.org/10.1002/wat2.1168 